\title{
Surface hardening by gaseous oxidizing of (Zr55Cu30Al10Ni5)98Er2 bulk-metallic glass
}

Haratian, Saber; Grumsen, Flemming B.; Villa, Matteo; Christiansen, Thomas L.; Somers, Marcel A.J.

Published in:

Journal of Alloys and Compounds

Link to article, DOI:

10.1016/j.jallcom.2019.06.042

Publication date:

2019

Document Version

Peer reviewed version

Link back to DTU Orbit

Citation (APA):

Haratian, S., Grumsen, F. B., Villa, M., Christiansen, T. L., \& Somers, M. A. J. (2019). Surface hardening by gaseous oxidizing of $\left(\mathrm{Zr}_{55} \mathrm{Cu}_{3} \mathrm{Al}_{1} \mathrm{Ni}_{5}\right)_{8} \mathrm{Er}_{2}$ bulk-metallic glass. Journal of Alloys and Compounds, 800, 456461. https://doi.org/10.1596/j..30llcom.20 198.06.042

\section{General rights}

Copyright and moral rights for the publications made accessible in the public portal are retained by the authors and/or other copyright owners and it is a condition of accessing publications that users recognise and abide by the legal requirements associated with these rights.

- Users may download and print one copy of any publication from the public portal for the purpose of private study or research.

- You may not further distribute the material or use it for any profit-making activity or commercial gain

- You may freely distribute the URL identifying the publication in the public portal 


\section{Accepted Manuscript}

Surface hardening by gaseous oxidizing of $\left(\mathrm{Zr}_{55} \mathrm{Cu}_{30} \mathrm{Al}_{10}{ }_{10}{ }\right)_{98} \mathrm{Er}_{2}$ bulk-metallic glass

Saber Haratian, Flemming B. Grumsen, Matteo Villa, Thomas L. Christiansen, Marcel A.J. Somers

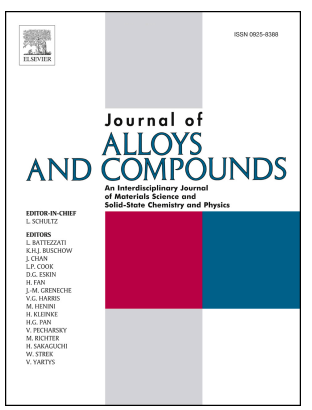

PII: S0925-8388(19)32107-3

DOI: $\quad$ https://doi.org/10.1016/j.jallcom.2019.06.042

Reference: JALCOM 50940

To appear in: Journal of Alloys and Compounds

Received Date: 31 October 2018

Revised Date: 2 May 2019

Accepted Date: 4 June 2019

Please cite this article as: S. Haratian, F.B. Grumsen, M. Villa, T.L. Christiansen, M.A.J. Somers, Surface hardening by gaseous oxidizing of $\left(\mathrm{Zr}_{55} \mathrm{Cu}_{30} \mathrm{Al}_{10} \mathrm{Ni}_{5}\right){ }_{98} \mathrm{Er}_{2}$ bulk-metallic glass, Journal of Alloys and Compounds (2019), doi: https://doi.org/10.1016/j.jallcom.2019.06.042.

This is a PDF file of an unedited manuscript that has been accepted for publication. As a service to our customers we are providing this early version of the manuscript. The manuscript will undergo copyediting, typesetting, and review of the resulting proof before it is published in its final form. Please note that during the production process errors may be discovered which could affect the content, and all legal disclaimers that apply to the journal pertain. 


\title{
Surface hardening by gaseous oxidizing of $\left(\mathrm{Zr}_{55} \mathrm{Cu}_{30} \mathrm{Al}_{10} \mathrm{Ni}_{5}\right)_{98} \mathrm{Er}_{2}$ bulk- metallic glass
}

\author{
Saber Haratian, Flemming B. Grumsen, Matteo Villa, Thomas L. Christiansen, Marcel A.J. \\ Somers \\ Department of Mechanical Engineering, Technical University of Denmark, Produktionstorvet b. \\ 425, 2800 Kgs. Lyngby, Denmark
}

Corresponding author: Saber Haratian

Ph.: +45 45252110

Fax: +45 45251961

Email: Sahara@mek.dtu.dk

\begin{abstract}
The present investigation addresses surface hardening and the oxidation behavior of $\left(\mathrm{Zr}_{55} \mathrm{Cu}_{30} \mathrm{Al}_{10} \mathrm{Ni}_{5}\right)_{98} \mathrm{Er}_{2}$ bulk-metallic glass (BMG) during gaseous oxidizing below the glass transition temperature $\left(<T_{\mathrm{g}}\right)$. The BMG was thermochemically surface engineered in controlled gaseous atmospheres imposing either an extremely low or an extremely high oxygen partial pressure. The hardened oxygen-containing case developing during oxidizing the BMG was characterized with X-ray diffraction, (electron) microscopy, energy dispersive spectroscopy and micro-hardness indentation. It was observed that oxidizing at a high $p_{O_{2}}$ resulted in the formation of an internal and an external oxidized zone; the latter can be minimized by applying a low $p_{\mathrm{O}_{2}}$. The inner oxide zone (IOZ) consisted mainly of a nano-crystalline dispersion of tetragonal $\mathrm{ZrO}_{2}$, while a porous $\mathrm{CuO}_{\mathrm{x}}$ network developed in the outer oxide zone (OOZ). The formation of copper oxide islands at the surface is interpreted as the result of outward diffusion of metallic $\mathrm{Cu}$ driven by a compressive stress gradient in the IOZ caused by volume expansion associated with $\mathrm{ZrO}_{2}$
\end{abstract}


1 (and $\mathrm{Al}_{2} \mathrm{O}_{3}$ ) formation. The results demonstrate that a hardened case (the IOZ) with a maximum hardness of $\sim 12 \mathrm{GPa}$ can be achieved. The depth distribution of oxygen is explained in terms of a concurrent crystallization of the BMG below $T_{\mathrm{g}}$.

Key words: $\mathrm{ZrCu}$-based bulk metallic glass; Internal and external oxidation; Oxidizing; Thermochemical treatment; Surface hardness

\section{Introduction}

Bulk metallic glasses (BMGs), have attracted considerable scientific and technological interest for their potential use in different functional and engineering applications, recognizing their peculiar combination of high strength and high elastic limit [1-9]. On the other hand, the application of BMGs is restricted by their intrinsic low fracture toughness [10-11]. Therefore, introducing appropriate techniques for enhancing the plasticity of these fragile materials is crucial with respect to their structural performance. Previously, efforts were reported to promote the plasticity of metallic glasses via altering their Poisson ratio (v) [12-14] or synthesizing metallic glass composites with a precipitated second phases [15-20]. Despite, the significant improvements of the fracture toughness achieved by increasing the Poisson ratio or making amorphous matrix composites, it is of interest to develop a practical technique to improve metallic glass plasticity without changing their initial metallic composition and sacrificing their unique properties. Recently, several surface treatments [21] were investigated in order to enhance the surface toughness of metallic glasses by effectively mitigating the propagation of shear bands and crack nucleation at the surface. These surface modification techniques, including mechanical surface treatment [22-25], surface coating [26-28] and thermal surface treatment [29-30], prevent shear band propagation through the introduction of compressive residual stresses in the surface region. 
Surface engineering by thermochemical treatment is widely applied to improve the performance of alloys and metals [31]. Thermochemical treatment entails changing the surface composition at elevated temperatures to obtain a hardened case, typically by the incorporation of interstitial elements. Low-temperature thermochemical surface treatment of metallic components can enhance the resistance against surface-initiated failure mechanisms, such as fatigue, wear and corrosion.

It is noted that, heretofore, several research activities have been performed to study the oxidation behavior of amorphous alloys in the air atmospheric conditions [32-35]. Nevertheless, thermochemical post-processing of metallic glasses in controlled oxidizing atmospheres has so far received limited attention. In this study, the low temperature surface hardening of $\left(\mathrm{Zr}_{55} \mathrm{Cu}_{30} \mathrm{Al}_{10} \mathrm{Ni}_{5}\right)_{98} \mathrm{Er}_{2}$ BMG using gaseous oxidizing is investigated. It is anticipated that the presence of $\mathrm{Zr}$ and $\mathrm{Al}$, which both have a high affinity for oxygen and a strongly negative Gibbs energy for oxide formation, enable the dissolution of an appreciable amount oxygen in the BMG, leading to a volume expansion that introduces compressive residual stress in the surface zone.

\section{Materials and methods}

As-cast Zr-based BMG with chemical composition $\left(\mathrm{Zr}_{55} \mathrm{Cu}_{30} \mathrm{Al}_{10} \mathrm{Ni}_{5}\right)_{98} \mathrm{Er}_{2}$ (at.\%) was provided by the Jiangxi Academy of sciences in China. The initial ingots were prepared using vacuum arc melting of high purity (99.9 wt. \%) elemental constituents in a Ti-gettered argon atmosphere. The synthesized ingots were re-melted several times to ensure compositional homogeneity. The homogenous ingots were subsequently cast into $2 \times 10 \times 60 \mathrm{~mm}^{3}$ plates using a copper mold casting method (Rapid Quench Machine System VF-RQT50, Makabe Co. Ltd. Japan). The glass transition $\left(T_{\mathrm{g}}\right)$ and the onset crystallization temperatures $\left(T_{\mathrm{x}}\right)$ were measured to 
$700 \mathrm{~K}$ and $740 \mathrm{~K}$, respectively as determined by differential thermal analysis in a Netzsch STA 449C thermal analyzer for a heating rate of $10 \mathrm{~K} \cdot \mathrm{min}^{-1}$ under a flow of argon at a flow rate of 50 $\mathrm{cm}^{3} \cdot \mathrm{min}^{-1}$. Gaseous oxidizing was carried out $10 \mathrm{~K}$ below the glass transition temperature in a proprietary gas mixture with either an extremely low $\left(p_{O_{2}}=10^{-26}\right.$ bar) or an extremely high oxygen partial pressure ( $p_{\mathrm{O}_{2}}=1648 \mathrm{bar}$ ). The oxygen partial pressures were realized chemically at a total gas pressure of 1 bar. Samples of $3 \times 3 \times 1 \mathrm{~mm}^{3}$ were treated for 4 and 16 hours at $690 \mathrm{~K}$ (i.e. $10 \mathrm{~K}$ lower than $T_{\mathrm{g}}$ ) in a thermogravimetric analyzer (Netzsch STA $449 \mathrm{~F} 3$ ). The samples were carefully polished to $1 \mu \mathrm{m}$ diamond and then cleaned with ethanol before thermochemical treatment. The amorphous and thermochemically oxidized samples were characterized with Xray diffractometry (XRD) using a Bruker D8 Discover equipped with $\mathrm{CuK}_{\alpha}$ radiation $(\lambda=0.15406$ $\mathrm{nm})$. Diffractograms were recorded in the $2 \theta$ range $25^{\circ}-90^{\circ}(2 \theta)$ at a step size of $0.04^{\circ}$ and a counting time of $8 \mathrm{~s}$ per step. The surface topography and the cross-section microstructure of the thermochemically oxidized samples were examined using scanning electron microscopy (SEM, JEOL JSM-5900) equipped with Oxford (Inca X-act) energy dispersive spectroscopy (EDS). The microstructure of the cross-section of the surface-treated BMG samples were investigated using a Neophot 32 (Zeiss, Jena) reflected light microscope. A JEOL 3000F transmission electron microscope (TEM) coupled with EDS detector was employed for supplementary characterization of the various zones formed in the oxidized BMG specimen treated at $690 \mathrm{~K}$ for $16 \mathrm{hr}$ in a high $p_{\mathrm{O}_{2}}$ atmosphere. An electron transparent TEM foil was prepared using a FEI Helios Nanolab with focused ion beam (FIB) milling using $\mathrm{Ga}^{+}$ions and an Omniprobe micro-manipulator. Initial rough FIB milling was carried out with a $30 \mathrm{kV}$ ion beam acceleration voltage and $20 \mathrm{nA}$ ion current. It should be noticed that the region of interest on the sample surface was protected from the excessive ion damage with the Pt-deposited layer. Thereafter, the lamella was lifted out 
with the Omniprobe and then mounted to a TEM Cu grid. The thinning process was performed using an ion beam current of $90 \mathrm{pA}-0.9 \mathrm{nA}$ on both sides of the extracted lamella. Finally, a low acceleration voltage $(2 \mathrm{kV})$ cleaning was done with a $24 \mathrm{pA}$ ion beam current to remove the residual $\mathrm{Ga}^{+}$ion damage on the lamella. To evaluate the hardened case, Vickers micro-hardness indentations (standard E 384-17) were determined on the cross-section of the thermochemically oxidized samples, using a FutureTech FM-700 Vickers indenter with 5 gf load and a dwell time of $10 \mathrm{~s}$.

\section{Results and Interpretation}

\subsection{X-ray diffraction of as-cast and thermochemically oxidized BMG}

The X-ray diffractograms of the as-cast $\left(\mathrm{Zr}_{55} \mathrm{Cu}_{30} \mathrm{Al}_{10} \mathrm{Ni}_{5}\right)_{98} \mathrm{Er}_{2}$ BMG and the specimens thermochemically oxidized in low and high oxygen partial pressure are shown in Fig. 1. The ascast material has a broad peak at $2 \theta \approx 38^{\circ}$, indicating that it is amorphous without detectable crystalline phases. The XRD results exhibit that after isothermal heating at $690 \mathrm{~K}$ for $4 \mathrm{hr}$ in a low oxygen partial pressure atmosphere, the amorphous phase devitrifies and forms crystalline $\mathrm{Zr}-\mathrm{Cu}, \mathrm{Zr}-\mathrm{Cu}-\mathrm{Al}$ and $\mathrm{Zr}-\mathrm{Ni}$ intermetallic phases, while oxidation results in the formation of tetragonal- $\mathrm{ZrO}_{2}\left(\mathrm{t}-\mathrm{ZrO}_{2}\right)$, which is ascribed to the high affinity of $\mathrm{Zr}$ for O. Prolonging the treatment to $16 \mathrm{hr}$, the intensity of $\mathrm{t}-\mathrm{ZrO}_{2}$ is amplified and only a small fraction of other crystalline phases can be detected. Evidently, the intermetallic compounds are located beyond the information depth of the applied X-rays. Further, the oxidation at a high chemical partial pressure of oxygen under identical isothermal heating condition leads to the formation of $\mathrm{t}-\mathrm{ZrO}_{2}$ and three types of copper oxides: $\mathrm{CuO}, \mathrm{Cu}_{2} \mathrm{O}$, and $\mathrm{Cu}_{4} \mathrm{O}_{3}$. Interestingly, in addition to the copper 
oxides formed during the thermochemical treatment, also diffraction peaks of pure copper are distinguished in the diffractograms. For the specimens oxidized at high $p_{\mathrm{O}_{2}}$, no intermetallic phases were found in the X-ray diffractogram, implying that the oxide layer is relatively thick as compared to the information depth of the applied X-radiation. From the intensity reduction of the main $\mathrm{t}-\mathrm{ZrO}_{2}$ peak $\left(2 \theta \approx 30^{\circ}\right)$ on prolonged oxidizing at high $p_{O_{2}}$ atmosphere it is concluded that the amount of $\mathrm{CuO}_{\mathrm{x}}$ at the surface increases with oxidizing time.

\subsection{Cross-sectional hardness measurement}

Microhardness-depth profiles obtained after oxidizing at $690 \mathrm{~K}$ for $4 \mathrm{hr}$ and $16 \mathrm{hr}$ in the thermogravimetric analyzer are given in Fig. 2. The effective case depths after oxidizing for 4 and $16 \mathrm{hr}$ at low $p_{\mathrm{O}_{2}}$ are $\sim 2 \mu \mathrm{m}$ and $\sim 10 \mu \mathrm{m}$, respectively, while at high $p_{\mathrm{O}_{2}}$ case depths of $\sim 18$ $\mu \mathrm{m}$ and $\sim 34 \mu \mathrm{m}$ were reached (see dotted vertical lines in Fig. 2). The hardness of the treated BMG reaches approximately $\sim 12 \mathrm{GPa}$ close to the surface, and decreases gradually until it reaches a steep drop to the hardness value of the un-oxidized BMG at the case-to-core transition. Evidently, changing the oxygen partial pressure has a large influence on the thickness of the hardened case depth.

\subsection{Microstructure characterization of the oxidized zones}

Microscopical investigations were carried out on the BMG that was thermochemically oxidized at $690 \mathrm{~K}$ for $16 \mathrm{hr}$ in a high $p_{\mathrm{O}_{2}}$ atmosphere. A secondary electron micrograph of the surface topography is presented in Fig. 3a. A gray porous oxide network appears to cover the surface. The chemical composition of the oxide network was probed with EDS point-to-point analyses 
and showed copper and oxygen, while other elements were virtually absent, indicating that the porous oxide network is formed by copper oxides. A light-optical image of a cross-section over the hardened case is provided in Fig. $3 \mathrm{~b}$ and shows the presence of island-like $(\mathrm{Cu} / \mathrm{CuO})$ particles lying on the top of the sample surface. Also, a $\mathrm{Cu}$-colored line directed perpendicularly to the surface is identified (see white arrow). This feature is interpreted as a Cu-filled crack (see discussion). For further cross-sectional inspection of the oxidized $\left(\mathrm{Zr}_{55} \mathrm{Cu}_{30} \mathrm{Al}_{10} \mathrm{Ni}_{5}\right)_{98} \mathrm{Er}_{2} \mathrm{BMG}$ Fig. 3c shows a back-scatter electron (BSE) micrograph and Fig. 3d EDS maps of the area marked in Fig. 3c. In addition, Fig. 3e shows composition-depth profiles determined with EDS. In the quantification of these profiles only the metallic components were considered, while the oxygen profile represents oxygen intensity relative to the maximum value. In Fig. 3c-3e, the case is subdivided in an inner oxide zone (IOZ) and an outer oxide zone (OOZ), based on the fraction of $\mathrm{Cu}$ revealed by EDS. The OOZ consists of island-like particles lying on the surface and of the top surface of the sample, appearing dark in Fig. 3c. Additionally, the IOZ is subdivided in three distinct zones denoted as I, II and III. The EDS results (Figs. 3d-e) show that the OOZ only contains copper and some oxygen. In the entire IOZ, the oxygen content decreases gradually while zirconium and aluminum are more or less homogeneously distributed. It is anticipated that the trend of increasing $\mathrm{Zr}$ and $\mathrm{Al}$ contents towards the surface in the IOZ, is a consequence of changes in density caused by internal oxidation and omitting $\mathrm{O}$ in the quantification of the EDS intensities of the metallic components. Zones I and II in the IOZ are closest to the surface and are depleted in copper. A sharp discontinuity in the $\mathrm{Cu}$ and $\mathrm{Ni}$ contents marks the transition between zones II and III in the EDS profile (marked by white arrow in Ni map). The oxygen content is highest in zone I and slightly lower (and constant) in zone II. In zone III the oxygen content shows a maximum at the location where the $\mathrm{Cu}$ content goes through a minimum and thereafter 
decreases with distance to the surface. Along with the decrease in oxygen content the BSE micrograph in Fig. $3 \mathrm{c}$ becomes brighter, indicating an increase in atomic density. The gradient in oxygen content is interpreted as a reduction of the amount of $\mathrm{Zr}$ (and $\mathrm{Al}$ ) available for internal oxide formation, because of the development of intermetallic compounds of $\mathrm{Zr}$ and $\mathrm{Al}$ prior to the arrival of oxygen. Although oxide formation eventually will prevail thermodynamically, the nucleation of $\mathrm{ZrO}_{2}$ is likely to be delayed, because i) the driving force for oxide formation is reduced if $\mathrm{Zr}$ is present in an intermetallic compound and ii) the reduction in free volume associated with devitrification and crystallization enhances strain energy evoked by internal oxidation. The transition from IOZ to oxygen-free BMG is very sharp, consistent with a sharp case-core transition in the hardness profile in Fig. $2 \mathrm{~b}$.

Another feature observed in the cross-section BSE micrograph in Fig. 3c is the presence of cracks perpendicular to the surface in zone I (dark lines marked by white arrows). Such cracks hint at a tensile stress imposed onto zone I.

Cross-sectional TEM bright-field images and their corresponding selected area electron diffraction (SAED) patterns are shown in Fig. 4 for the OOZ and in zone II of the IOZ. Closest to the surface the SAED patterns show the presence of monoclinic $\mathrm{CuO}$ and tetragonal $\mathrm{Cu}_{4} \mathrm{O}_{3}$, while zone I in the $\mathrm{IOZ}$ contains nano-crystalline $\mathrm{t}-\mathrm{ZrO}_{2}$.

\section{Discussion}

The results obtained on oxidizing $\left(\mathrm{Zr}_{55} \mathrm{Cu}_{30} \mathrm{Al}_{10} \mathrm{Ni}_{5}\right)_{98} \mathrm{Er}_{2} \mathrm{BMG}$ at a temperature below $T_{\mathrm{g}}$ show that the incorporation of oxygen leads to the development of an IOZ consisting of nanocrystalline $\mathrm{t}-\mathrm{ZrO}_{2}$ within the $\mathrm{BMG}$ and an $\mathrm{OOZ}$ consisting of $\mathrm{Cu}$-based oxides. Although the 
oxidizing temperature was chosen $10 \mathrm{~K}$ below $T_{\mathrm{g}}$, the development of crystalline intermetallic phases was observed for the sample oxidized at a low $p_{O_{2}}$ for $4 \mathrm{~h}$, where the thinnest IOZ has developed. It is likely that such crystallization also occurred for the other oxidizing condition, but it remained unobserved because of the limited information depth of the applied X-radiation. Nevertheless, under the present oxidizing conditions the developing IOZ is the result of a competition between the crystallization of intermetallic compounds and internal oxidation of strong oxide forming alloying elements.

The strongest oxide formers in the investigated BMG are $\mathrm{Zr}$ and Al. The Gibbs energy for oxide formation (per mol $\mathrm{O}_{2}$ ) is slightly more negative for $\mathrm{ZrO}_{2}$ than for $\mathrm{Al}_{2} \mathrm{O}_{3}$. Hence, for the present BMG, which contains $\sim 55$ at. $\% \mathrm{Zr}$ and $\sim 10$ at. $\% \mathrm{Al}, \mathrm{ZrO}_{2}$ is the thermodynamically most stable oxide, which could explain why it is the only oxide present after oxidation at a low $p_{\mathrm{O}_{2}}$ for $4 \mathrm{~h}$ (Fig. 1). As no indications for the development of $\mathrm{Al}_{2} \mathrm{O}_{3}$ were found, not even after prolonged oxidation or at higher $p_{O_{2}}$, it is concluded that $\mathrm{Al}_{2} \mathrm{O}_{3}$ is either amorphous or it is dissolved in $\mathrm{ZrO}_{2}[36]$.

The case depth of the IOZ was observed to depend strongly on the $p_{\mathrm{O}_{2}}$ in the oxidizing gas (Fig. 2 and section 3.2). For the low $p_{\mathrm{O}_{2}}$, the hardened case depth is increased about 4 times on prolonging the oxidizing treatment by a factor 4 ; for the high $p_{\mathrm{O}_{2}}$, the hardened case depth is about doubled when the duration is quadrupled. These observations suggest that for the oxidizing conditions at low $p_{\mathrm{O}_{2}}$, growth of the case depth (the IOZ) is not diffusion controlled, but rather controlled by the surface reaction, i.e. the transfer of oxygen from the gas to the solid. On the other hand, the observations for the high $p_{\mathrm{O}_{2}}$ are consistent with diffusion-controlled growth of 
1 the IOZ. The diffusing species that governs the thickness of the IOZ for the high $p_{\mathrm{O}_{2}}$ is most 2 likely atomic oxygen.

The development of an $\mathrm{OOZ}$ consisting of $\mathrm{Cu}$-based oxides and a redistribution of $\mathrm{Cu}$ in the IOZ (especially zones I and II) is explained as follows. The development of nano-crystalline t$\mathrm{ZrO}_{2}$ in the IOZ leads to a volume expansion. This volume expansion is accommodated by compressive stress in the IOZ, which leads to a higher chemical potential for the components in IOZ than in the unaffected regions, i.e. the surface and the interior of the BMG. Consequently, a

driving force for diffusion out of the IOZ is established and those components which are not bound to oxides, mainly $\mathrm{Cu}$ and $\mathrm{Ni}$, will diffuse out of the IOZ. For oxidizing at high $p_{\mathrm{O}_{2}}$ the $\mathrm{Cu}$ arriving at the surface will oxidize to $\mathrm{Cu}$-oxide and develop the porous network that forms the $\mathrm{OOZ}$, while $\mathrm{Cu}$ does not oxidize at low $p_{\mathrm{O}_{2}}$. Also the observation of metallic $\mathrm{Cu}$ in microcracks can be explained by the outward diffusion of $\mathrm{Cu}$ towards a free (crack) surface (Fig. 3b). If no oxidation occurs of $\mathrm{Cu}$ it implies that the local $p_{\mathrm{O}_{2}}$ is not sufficiently high to stabilize $\mathrm{Cu}$-oxide. Thus, microcracks can in principle be "repaired" by this self-healing mechanism. This phenomenon has also been recently reported for air-oxidation of the noble-metal containing $\mathrm{Zr}$ based BMG by the present authors [37].

The development of micro-cracks perpendicular to the surface was only observed in zone I of the IOZ, and indicates that tensile stresses have been present in this region. In order to understand how these tensile stresses were introduced in zone I of the IOZ it is important to explain the subdivision of the IOZ in zones I, II and III. The subdivision is most likely associated with the competition between internal oxidation and the nucleation of intermetallic compounds and devitrification in the core. Clearly, the volume changes in the various zones 
within the IOZ will be different. Apparently, zone I has experienced a volume expansion imposed by the underlying zones II and III while they expanded on internal oxidation. This is suggested to be caused as follows. Presuming that no intermetallic compounds formed in zone I prior to internal oxidation of $\mathrm{Zr}$ (and $\mathrm{Al}$ ), the devitrification deeper in the material will lead to additional compressive stress imposed onto zone $\mathrm{I}$, resulting in an additional flux of $\mathrm{Cu}$ out of this region to comply with these stresses and reduce them. Then, on subsequent formation of $\mathrm{ZrO}_{2}$ deeper in the (partly) devitrified and crystallized BMG, the occurring volume expansion leads to imposing tensile straining of zone I, causing crack initiation perpendicular to the surface.

Obviously, the hardness profiles in Fig. 2 correlate with the oxygen content in the IOZ (Fig. 3e). The highest oxygen content corresponds to the highest hardness in zone I. In zone II the hardness is constant at about $1060 \mathrm{HV}$, while the hardness decreases gradually in zone III along with the reduction in oxygen content, to fall abruptly at the transition from IOZ to oxygen-free alloy.

\section{Conclusion}

The effect of gaseous oxidizing as a thermochemical treatment of $\left(\mathrm{Zr}_{55} \mathrm{Cu}_{30} \mathrm{Al}_{10} \mathrm{Ni}_{5}\right)_{98} \mathrm{Er}_{2}$ BMG below the glass transition temperature $\left(T_{\mathrm{g}}\right)$ was investigated for different treatment durations in low and high oxygen partial pressure $\left(p_{O_{2}}\right)$. It was demonstrated that for oxidizing at a low oxygen pressure internal oxidation of $\mathrm{Zr}$ to tetragonal $\mathrm{ZrO}_{2}$ occurs in competition with crystallization of the BMG, despite an oxidizing temperature below $T_{g}$. The growth kinetics of the inner oxide zone (IOZ) for low $p_{\mathrm{O}_{2}}$ appears to be linear, suggesting that the oxygen transfer to the BMG is rate determining. For high $p_{\mathrm{O}_{2}}$ two different oxide zones formed at the surface: an outer oxide zone (OOZ) consisting of porous $\mathrm{CuO}_{\mathrm{x}}$ islands and an $\mathrm{IOZ}$ which is subdivided in 
1

2

three subzones. The presence of copper oxides in the $\mathrm{OOZ}$ is attributed to the outward diffusion of copper from the inner oxide zone as a result of compressive growth stresses induced by the formation of $\mathrm{ZrO}_{2}$. The subdivision of the $\mathrm{IOZ}$ is suggested to be the outcome of the competition between internal oxidation of $\mathrm{Zr}$ (and $\mathrm{Al}$ ) and devitrification and crystallization of the BMG. Parabolic growth kinetics of the IOZ appears to apply, indicating (oxygen) diffusion controlled growth.

The dissolution of oxygen into the MG substrate effectively enhances the surface hardness by forming the $\mathrm{ZrO}_{2}$ in the IOZ. The hardness in the oxygen-containing case increased significantly from approximately $\sim 600 \mathrm{HV}$ in the core of un-oxidized BMG to $\sim 1200 \mathrm{HV}$.

\section{Acknowledgments}

Villum Fonden is gratefully acknowledged for financial support under Grant No. 13253. The authors acknowledge the Institute of Applied Physics, Jiangxi Academy of Sciences, Nanchang in China for providing the starting material.

\section{References:}

[1] M. F. Ashby and A. L. Greer, "Metallic glasses as structural materials," Scr. Mater., vol. 54, no. 3, pp. 321326, 2006.

[2] M. M. Trexler and N. N. Thadhani, "Mechanical properties of bulk metallic glasses,” Prog. Mater. Sci., vol. 55, no. 8, pp. 759-839, 2010.

[3] A. R. Yavari, J. J. Lewandowski, and J. Eckert, “Mechanical Properties of Bulk Metallic Glasses,” vol. 32, no. August, pp. 635-638, 2007.

[4] A. L. Greer and E. Ma, "Bulk Metallic Glasses : At the Cutting Edge of metals research," MRS Bull., vol. 32, no. August, pp. 611-619, 2007.

[5] M. Telford, “The case for bulk metallic glass,” Mater. Today, vol. 7, no. 3, pp. 36-43, 2004.

[6] J. Schroers, G. Kumar, T. M. Hodges, S. Chan, and T. R. Kyriakides, "Bulk metallic glasses for biomedical 
applications,” Jom, vol. 61, no. 9, pp. 21-29, 2009.

[7] A. Inoue and A. Takeuchi, "Recent development and application products of bulk glassy alloys," Acta Mater., vol. 59, no. 6, pp. 2243-2267, 2011.

[8] W. Zhang, A. Inoue, and X. M. Wang, "Developments and Applications of Bulk Metallic Glasses," Rev. Adv. Mater. Sci., vol. 18, pp. 1-9, 2008.

[9] H. F. Li and Y. F. Zheng, "Recent advances in bulk metallic glasses for biomedical applications," Acta Biomater., vol. 36, pp. 1-20, 2016.

[10] Z. Q. Liu and Z. F. Zhang, "Strengthening and toughening metallic glasses: The elastic perspectives and opportunities," J. Appl. Phys., vol. 115, no. 16, pp. 0-11, 2014.

[11] J. Xu, U. Ramamurty, and E. Ma, “The fracture toughness of bulk metallic glasses,” Jom, vol. 62, no. 4. pp. 10-18, 2010.

[12] S. V. Madge, D. V. Louzguine-Luzgin, J. J. Lewandowski, and A. L. Greer, "Toughness, extrinsic effects and Poisson's ratio of bulk metallic glasses," Acta Mater., vol. 60, no. 12, pp. 4800-4809, 2012.

[13] S. J. Poon, A. Zhu, and G. J. Shiflet, "Poisson's Ratio and Intrinsic Plasticity of Metallic Glasses," Appl. Phys. Lett., vol. 92, no. 26, pp. 2006-2009, 2008.

[14] G. N. Greaves, A. L. Greer, R. S. Lakes, and T. Rouxel, "Poisson's ratio and modern materials," Nat. Mater., vol. 10, no. 11, pp. 823-837, 2011.

[15] D. C. Hofmann, "Bulk Metallic Glasses and Their Composites: A Brief History of Diverging Fields," J. Mater., vol. 2013, p. e517904, 2013.

[16] D. C. Hofmann et al., "Designing metallic glass matrix composites with high toughness and tensile ductility," Nature, vol. 451, no. 7182, pp. 1085-1089, 2008.

[17] J. Z. Jiang, D. Hofmann, D. J. Jarvis, and H. J. Fecht, "Low-Density High-Strength Bulk Metallic Glasses and Their Composites: A Review," Adv. Eng. Mater., vol. 17, no. 6, pp. 761-780, 2015.

[18] G. He, J. Eckert, W. Löser, and L. Schultz, "Novel Ti-base nanostructure-dendrite composite with enhanced plasticity," Nat. Mater., vol. 2, no. 1, pp. 33-37, 2003.

[19] J. Eckert et al., "High strength ductile Cu-base metallic glass," Intermetallics, vol. 14, no. 8-9, pp. 876-881, 2006.

[20] J. Eckert, J. Das, S. Pauly, and C. Duhamel, "Mechanical properties of bulk metallic glasses and composites,” J. Mater. Res., vol. 22, no. 2, pp. 285-301, 2007.

[21] T. G. Nieh, Y. Yang, J. Lu, and C. T. Liu, "Effect of surface modifications on shear banding and plasticity in metallic glasses: An overview,” Prog. Nat. Sci. Mater. Int., vol. 22, no. 5, pp. 355-363, 2012.

[22] Y. Zhang, W. H. Wang, and A. L. Greer, "Making metallic glasses plastic by control of residual stress," vol. 5, no. November, pp. 857-860, 2006.

[23] J. Fu, Y. Zhu, C. Zheng, R. Liu, and Z. Ji, "Effect of laser shock peening on the compressive deformation and plastic behavior of Zr-based bulk metallic glass," Opt. Lasers Eng., vol. 86, pp. 53-61, 2016.

[24] C. Ma et al., "Increasing fracture strength in bulk metallic glasses using ultrasonic nanocrystal surface modification," vol. 718, pp. 246-253, 2017.

[25] F. O. Méar, B. Doisneau, A. R. Yavari, and A. L. Greer, "Structural effects of shot-peening in bulk metallic glasses," vol. 483, pp. 256-259, 2009.

[26] W. Chen, K. C. Chan, P. Yu, and G. Wang, "Encapsulated Zr-based bulk metallic glass with large plasticity,” Mater. Sci. Eng. A, vol. 528, no. 6, pp. 2988-2994, 2011. 
[27] W. Chen, K. C. Chan, S. H. Chen, S. F. Guo, W. H. Li, and G. Wang, "Plasticity enhancement of a Zr-based bulk metallic glass by an electroplated Cu / Ni bilayered coating," vol. 552, pp. 199-203, 2012.

[28] L. W. Ren et al., "Enhancement of plasticity in Zr-based bulk metallic glasses electroplated with copper coatings," Intermetallics, vol. 57, pp. 121-126, 2015.

[29] J. Fan, A. Chen, J. Wang, J. Shen, and J. Lu, "Improved plasticity and fracture toughness in metallic glasses via surface crystallization,” Intermetallics, vol. 19, no. 10, pp. 1420-1427, 2011.

[30] G. Wu et al., "Induced multiple heterogeneities and related plastic improvement by laser surface treatment in CuZr-based bulk metallic glass," Intermetallics, vol. 24, pp. 50-55, 2012.

[31] E. J. Mittemeijer and M. A. J. Somers, Thermochemical Surface Engineering of Steels. Woodhead Publishing Limited, 2015.

[32] Z. Xu, Y. Xu, A. Zhang, J. Wang, and Z. Wang, "Oxidation of amorphous alloys," J. Mater. Sci. Technol., vol. 34, no. 11, pp. 1977-2005, 2018.

[33] Y. Xu et al., "Natural oxidation of amorphous $\mathrm{Cu}_{\mathrm{x}} \mathrm{Zr}_{1-\mathrm{x}}$ alloys," Appl. Surf. Sci., vol. 457, no. June, pp. 396$402,2018$.

[34] W. Kai, F. P. Cheng, Y. T. Chen, R. T. Huang, H. H. Huang, and W. Zhang, "Air-oxidation of an amorphous $\mathrm{Fe}_{70} \mathrm{C}_{10} \mathrm{P}_{10} \mathrm{~B}_{5} \mathrm{Mo}_{5}$ alloy at $400-500{ }^{\circ} \mathrm{C}$," J. Alloys Compd., vol. 763, pp. 209-215, 2018.

[35] K. R. Lim et al., "Oxidation resistance of the supercooled liquid in $\mathrm{Cu}_{50} \mathrm{Zr}_{50}$ and $\mathrm{Cu}_{46} \mathrm{Zr}_{46} \mathrm{Al}_{8}$ metallic glasses," J. Mater. Res., vol. 27, no. 08, pp. 1178-1186, 2012.

[36] S. Moreau, M. Gervais, and A. Douy, "Formation of metastable solid solution in the $\mathrm{ZrO}_{2}$ rich part of the system $\mathrm{ZrO}_{2}-\mathrm{Al}_{2} \mathrm{O}_{3} . "$ pp. 625-631, 1997.

[37] S. Haratian, F. B. Grumsen, M. Villa, T. L. Christiansen, and M. A. J. Somers, "Self-repair by stressinduced diffusion of noble elements during oxidation of $\mathrm{Zr}_{48} \mathrm{Cu}_{36} \mathrm{Al}_{8} \mathrm{Ag}_{8}$ bulk metallic glass," Scr. Mater., vol. 164, pp. 126-129, 2019.

\section{Figure captions:}

Figure 1. The X-ray diffractograms of the as-cast and thermochemically oxidized $\left(\mathrm{Zr}_{55} \mathrm{Cu}_{30} \mathrm{Al}_{10} \mathrm{Ni}_{5}\right)_{98} \mathrm{Er}_{2}$ (at.\%) BMG.

Figure 2. Microhardness profiles as a function of depth for $\left(\mathrm{Zr}_{55} \mathrm{Cu}_{30} \mathrm{Al}_{10} \mathrm{Ni}_{5}\right)_{98} \mathrm{Er}_{2} \mathrm{BMG}$ thermochemically oxidized at $690 \mathrm{~K}$ for 4 and $16 \mathrm{hr}$ in (a) low (b) high oxygen partial pressure atmospheres $\left(p_{\mathrm{O}_{2}}\right)$.

Figure 3. (a) Secondary electron (SE) micrograph of surface morphology of $\left(\mathrm{Zr}_{55} \mathrm{Cu}_{30} \mathrm{Al}_{10} \mathrm{Ni}_{5}\right)_{98} \mathrm{Er}_{2} \mathrm{BMG}$ thermochemically oxidized at $690 \mathrm{~K}$ for $16 \mathrm{hr}$ in high $p_{\mathrm{O}_{2}}$ atmosphere; (b) Optical image of the cross-section view demonstrating a self-healed microcrack with metallic $\mathrm{Cu}$; (c) Cross-sectional BSE micrograph of the oxide zones formed on $\left(\mathrm{Zr}_{55} \mathrm{Cu}_{30} \mathrm{Al}_{10} \mathrm{Ni}_{5}\right)_{98} \mathrm{Er}_{2}$ BMG after oxidizing treatment at $690 \mathrm{~K}$ for $16 \mathrm{hr}$ (d) EDS mapping of 
1 the selected area in c; (e) atomic fraction of metallic components (left vertical scale) and 2 oxygen intensity profile (right vertical scale).

3 Figure 4. Cross-sectional TEM bright-field image of thermochemically oxidized $4 \quad\left(\mathrm{Zr}_{55} \mathrm{Cu}_{30} \mathrm{Al}_{10} \mathrm{Ni}_{5}\right)_{98} \mathrm{Er}_{2}$ BMG after applying the treatment at $690 \mathrm{~K}$ for $16 \mathrm{hr}$ and their typical 5 corresponding SAED patterns which have been obtained from different positions: (a) position 1 $6 \quad$ (b) position 2 (c) position 3. 


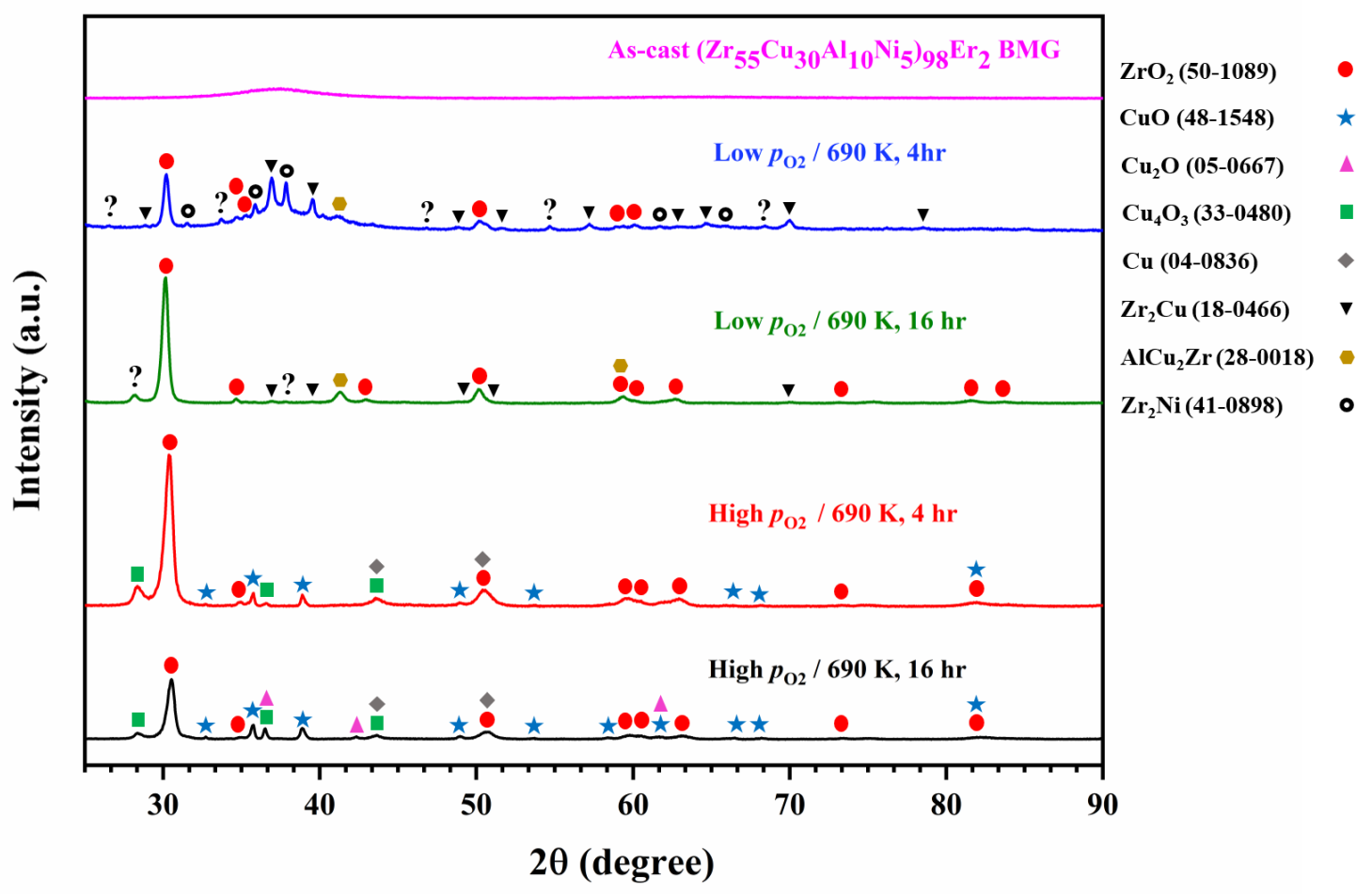



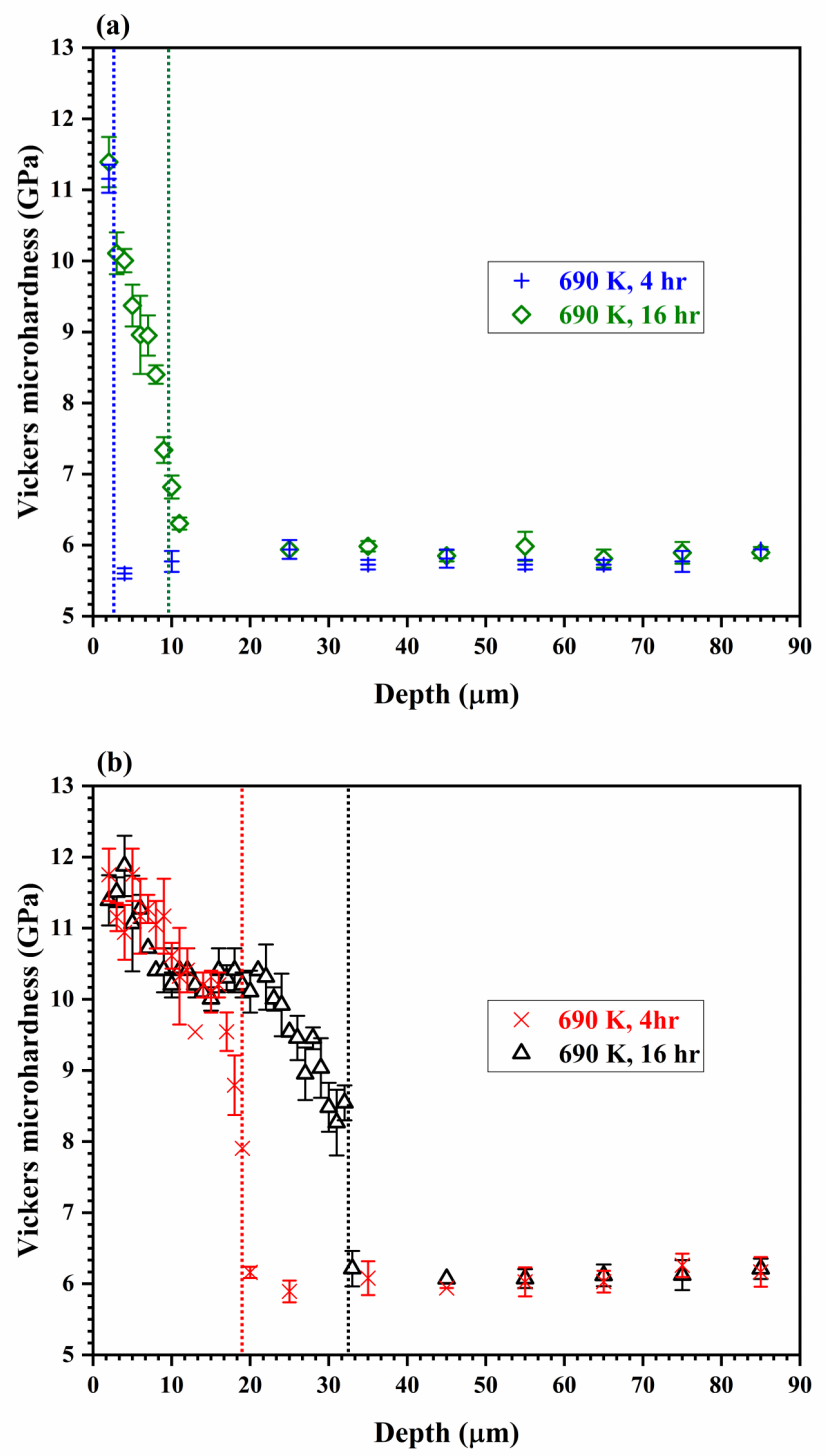


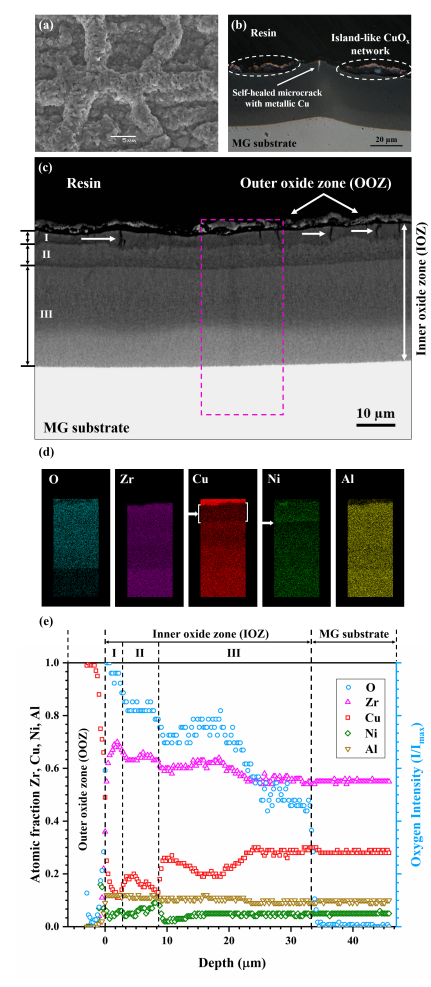



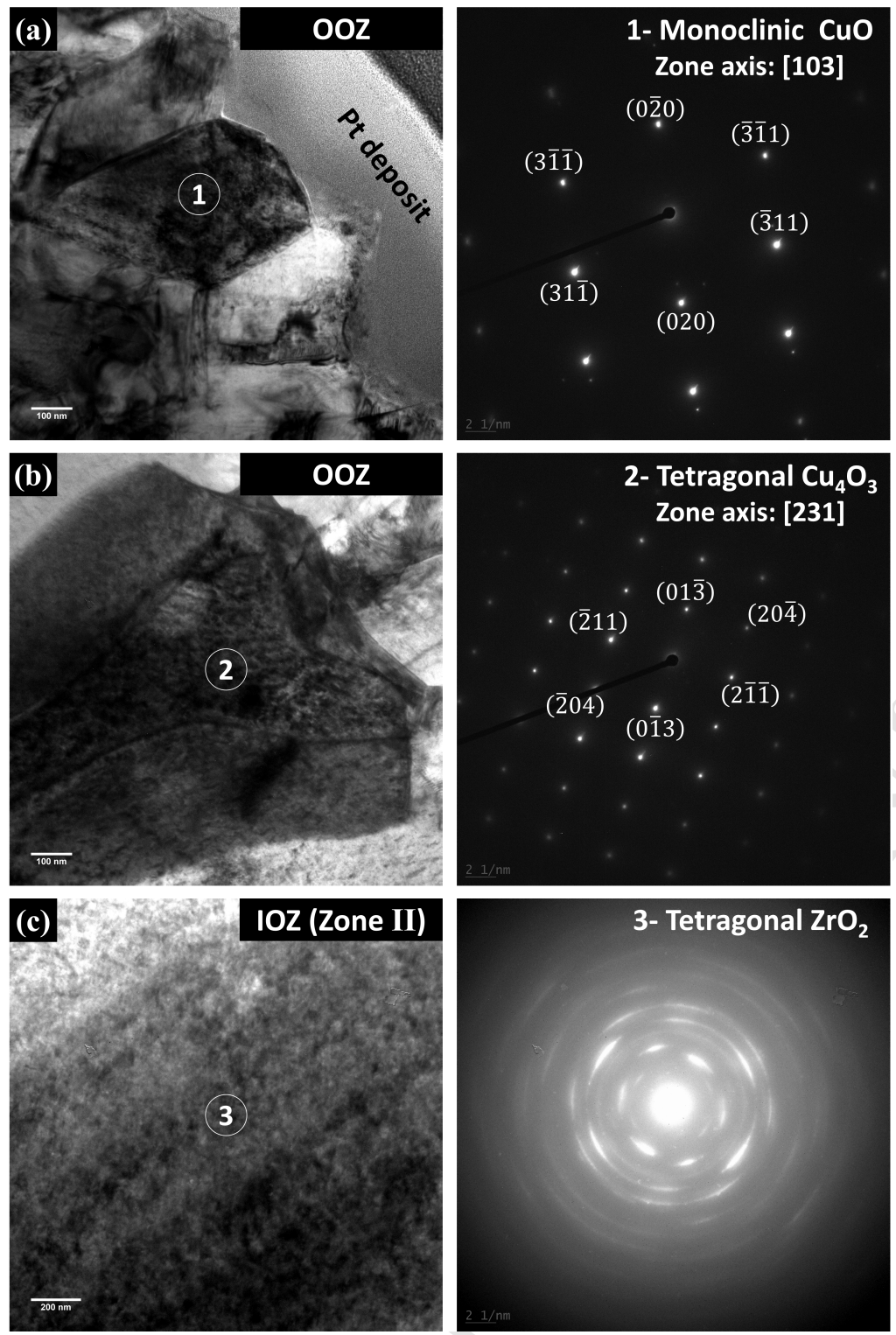


\section{Highlights}

1. Surface hardness of $\mathrm{Zr}$-based BMG can be enhanced by oxidizing treatment below $T_{\mathrm{g}}$.

2. Oxygen dissolution in $\mathrm{BMG}$ (high $p_{\mathrm{O}_{2}}$ ) results in the formation of two oxide zones.

3. $\mathrm{CuO}_{\mathrm{x}}$ formation is ascribed to outward stress-induced diffusion of $\mathrm{Cu}$.

4. The growth of the inner oxide zone is accompanied by the partial devitrification. 